\title{
Итальянская доктрина международного права (Часть 1)
}

Шумилов В.M.*

(Обзор учебника: Бенедетто Конфорти. «Международное право», 5 издание, изд-во «Эдиторьяле Шьентифика», Неаполь, 1999, 446 стр.; Napoli, 1999)

Предисловие. Международное право как явление реальности и как наука переживает в настоящее время новый этап развития. В России один за другим выходят авторские учебники международного права, расширяется поток специализированной литературы по отдельным аспектам международно-правового регулирования.

Вместе с тем для российской литературы по международному праву характерен один большой недостаток: в ней в системном виде не представлены или почти не представлены современные международно-правовые концепции, которые разделяются доктриной и практикой в других странах.

Возникла идея: посмотреть, что думают о международном праве и об отдельных его проблемах зарубежные ученые, познакомить российский корпус юристов-международников со взглядами и международно-правовой позицией представителей различных иностранных юридических школ, ввести в научный и педагогический оборот новую информацию.

Перед вами первый результат такой попытки. Это - краткий обзор классического учебника (монографии) «Международное право», автором которого является известный итальянский ученый Б. Конфорти.

Это - не точный перевод учебника, а своего рода его свободный пересказ, изложение, очень близкое по смыслу и по терминологии к оригиналу. Из учебника заимствованы наиболее интересные, с точки зрения российского читателя, положения, дающие представление как об общем подходе к международному праву, так и к отдельным важным вопросам.

\footnotetext{
- Шумилов Владимир Михайлович - д.ю.н., проф., зав. кафедрой Всероссийской академия внешней торговли.
} 
Итак, вот точка зрения Б. Конфорти (Италия).

Понятие международного права: терминологический аспект. В первом приближении международное право (МП) можно определить как право (или «режим» - ordinamento) «сообщества государств» «comunita degli Stati», т.е. «международного сообщества».

Данный комплекс норм - право международного сообшества (diritto della comunita internazionale) - образуется в надгосударственном порядке и обязывает государства к сотрудничеству с другими государствами. Сами же государства обязаны привести свое внутреннее законодательство в соответствие с международным правом.

Обычно считается, что МП регулирует отношения между государствами. Это верно с формальной точки зрения в том смысле, что нормы МП создают права и обязанности для государств. Однако сегодня данное выражение неверно с материальной точки зрения в том смысле, что МП регулирует уже не только «отношения между государствами» (interstatali), но и отношения «межличностные» (interindividuali).

Когда-то межличностные отношения были почти исключительно внутренним делом государств, тогда как под межгосударственными отношениями подразумевали внешние дела: дипломатический иммунитет, образование союзов, правила ведения военных действий и т.п.

Сегодня все по-другому. Многие стороны жизни - торговля, экономика, социальные отношения - интернационализируются, передаются под международное регулирование, и МП в таких условиях все больше превращается в право, регулирующее отношения между субъектами внутреннего права. В право, которым должна руководствоваться в первую очередь судебная власть той или иной страны.

Международное публичное и международное частное право. МП зовется публичным в противопоставление «международному частному праву», хотя различие между ними провести нетрудно.

МЧП не стоит над государствами, не является правом сообщества государств. МЧП состоит из таких норм внутригосударственного права, которые разграничивают сферу внутреннего права одного государства от сферы внутреннего права другого.

МЧП указывает, когда должны применяться начиональные нормы внутригосударственного права, а когда нормы иностранного внутреннего права.

Так, норма МЧП, содержащаяся в Гражданском кодексе Италии (с изменениями 1995 г.) гласит: «Правосубъектность физических лиц оп- 
ределяется их национальным законодательством» (ст. 20 ГК). Это означает, что итальянский судья в отношении вопроса о правосубъектности физического лица применит нормы ГК и друтих итальянских законов, если данное лицо - гражданин Италии. Если же лицо окажется иностранцем, итаґянский судья применит соответствующее иностранное право.

Итак, МЧП принадлежит к внутреннему правопорядку, тогда как МП - к правопорядку сообшества государств.

Конечно, МП устремлено на регулирование и межличностных отношений, но это означает, что государство в МП обязано приспособить международные нормы к регулированию тех отношений, которые регулируются нормами внутреннего права. Отсюда возникает проблема приспособления внутреннего права к международному праву.

Следует обратить внимание, что к МЧП относятся нормы, которые отделяют не только гражданско-правовую, но и публично-правовую сферу внутреннего правопорядка от правопорядка международного. В связи с этим к МЧП, например, будут относиться нормы, указывающие, в каких случаях внутренний уголовный закон применяется к преступлениям, совершенным иностранцами или совершенным за пределами национальной территории. Особенность лишь в том, что в публично-правовой сфере государства стремятся по максимуму возможного исключить применение иностранного права.

Что же касается определения «публичный» применительно к МП, то такое определение может искажать картину, поскольку сегодня МП не является ни публичным, ни частным (это разделение годится только для внутреннего права). МП сегодня - это право международного сообщества.

Источники МП. Следует разделять международное право с точки зрения его регулятивной функции на общее МП и партикулярное МП.

Общее МП адресовано всем государствам. Нормой (принципом) общего МП считается норма, принятая преобладающим большинством государств (не обязательно исключительно всеми).

Партикулярное МП состоит из норм, регулирующих отношения узкого круга субъектов, в основном тех субъектов, которые сами принимают участие в создании этих норм.

В статье 10 Конституции Италии предусмотрено, что «внутренний правопорядок в Италии подчиняется общепризнанным нормам МП».

Общепризнанные нормы имеют обычно-правовой характер. Они сформировались благодаря повторяющейся практике. Констатировать 
наличие международно-правового обычая можно, только если он подтверждается постоянной практикой государств. Международно-правовой обычай (consuetudine) в международном правопорядке представляет собой первичный источник, или «источник первого уровня».

Среди норм международно-правового обычая много норм «вспомогательных», «технических» (strumentali), т.е. таких норм, которые регулируют действительность и действие договоров - «источников второго уровнян.

Среди международно-правовых норм мало материальных норм (materiali), т.е. таких норм, которые непосредственно налагают на государства права и обязанности.

Помимо международно-правовых обычаев общего характера, существуют и партикулярные обычаи. Однако основной массив международно-правовых норм - это нормы, происходящие из международных договоров и действующие только между государствами - участниками таких договоров. Международный договор стоит в иерархии источников ниже международного обычая (точно так же, как во внутреннем праве договорное право стоит ниже законов). Тот факт, что общее международное право бедно, а основная масса отношений регулируется в договорном порядке, наводит на мысль о господстве некоторой анархичности отношений в международном сообществе.

Ниже договоров в иерархии источников стоят акты (procedimenti), предусмотренные договорами, в частности акты, принимаемые международными организациями или органами межгосударственных объединений. Это «источники третьего уровня». Примером могут служить акты органов ЕС. Сила таких актов проистекает из международных договоров, и действуют нормы таких актов только в отношениях между сторонами договоров.

Данный вид источников приобретает особую важность в наши дни. Италия, подписав в 1957 г. Римский договор об учреждении Европейского Экономического Сообщества (ЕЭС), тем самым взяла на себя обязательство исполнять решения органов ЕЭС (теперь - ЕС).

Функция МП по разрешению споров. Право международного сообщества реализует функцию разрешения споров преимушественно арбитражными, а не судебными методами. Практически не существует (за некоторыми исключениями) международных судебных органов, к которым одно государство могло бы прибегнуть против другого 
государства, если только это другое государство само не' согласилось на юрисдикцию такого органа.

Предохранительная функция МП. Функция по обеспечению реализации международно-правовых норм и недопушению нарушений, т.е. предохранительная функция МП, почти всецело покоится на средствах, которые можно было бы отнести к категории «самозащиты» (autotutela).

Обязательный характер МП. До сих пор зачастую ставится под сомнение, что МП является собственно правом. Скептики указывают на необязательность МП, на его неспособность принудить государства, особенно отдельные «великие державы», к соблюдению международных норм. Однако обязательность МП обеспечивается практически всеми государствами посредством внутреннего права. Так, договоры, заключаемые Италией, становятся предметом законов, которые обязывают применять договоры. А если так, то соблюдение МП в первую очередь зависит от судейского корпуса, поскольку именно судьи в максимально возможной степени задействуют гарантии соблюдения МП и его верховенства над правом внутригосударственным.

Между тем МП как право международного сообщества так до сих пор и не располагает правовыми средствами, которыми можно было бы эффективно отреагировать на нарушение международных норм. Назрела необходимость уходить от положения, когда любое отдельное государство свободно в том, чтобы принимать или не принимать на себя какие-либо международные обременения.

Эпоха, когда МП воспринималось как право самоограничения отдельных государств, закончилась.

Субъекты МП. Когда мы говорим о государстве как субъекте МП, следует различать понятия:

а) «государство» в смысле «сообщество» и

б) «государство» в смысле «аппарат», «организачия».

«Государство - сообщество» понимается как совокупность людей, проживающих на определенной территории и подчиняющихся единым законам.

«Государство - аппарат», «государство - организация» представляет собой совокупность государственных органов и должностных лиц, осуществляющих публичную власть в отношении людей.

Понятие «субъект МП» относится только к «государству - аппарату/организации», причем к государству, которое в действительности осуществляет свою власть на собственной территории. 
Правительства в изгнании, например, такой властью не обладают и потому не являются субъектами МП. То же относится к разного рода комитетам или фронтам национального освобождения, имеюшим штабквартиры за рубежом. Так, Организации освобождения Палестины (ООП) многие годы располагалась в Тунисе. Кассационный суд Италии в 1985 г. вынес решение, в соответствии с которым ООП и подобные организации обладают ограниченной правосубъектностью, необходимой только для того, чтобы «вести переговоры с государствами на основе равенства о способах и времени самоопределения народов, политически контролируемых ими, в рамках реализации принципа самоопределения народов, являющегося обычно-правовой нормой когентного характера».

Другим признаком государства - субъекта МП является его внешняя независимость, суверенитет. В связи с этим не могут рассматриваться в качестве субъектов МП территориальные образования федеративных государств. Бывает, что такие образования управомочены федеральной конституцией заключать договоры с друтими государствами (см. ст. 4, п. 10 Конституции США, ст. 9 Конституции Швейцарии), однако при этом они действуют в строго очерченных рамках в интересах федеративного государства в целом, выступая в качестве его органов.

Положение федеративного государства следует отличать от конфедерачии, представляющей собой союз (объединение) независимых, суверенных государств, создаваемое, как правило, в целях обшей обороны или внешней политики.

Известно много исторических примеров конфедераций. Однако Содружество Независимых Государств (СНГ), судя по его уставным документам, - не конфедерация, а организация, имеющая целью координацию и развитие сотрудничества. Это же можно сказать о проекте «конфедерации» между Хорватией и Боснией-Герцеговиной, как она предусмотрена в предварительном Договоре 1994 г.

Впрочем, понятие «независимости» в наши дни - во времена «взаимозависимости» - весьма условно. Формальным признаком независимости можно считать положение, при котором внутренний правопорядок определяется самим государством, его конституцией, а не правом и конституцией другого государства. И размеры государства не имеют значения: Сан-Марино или Лихтенштейн в этом смысле все равно остаются субъектами МП.

Действительное управление страной и независимость в осуществлении власти на своей территории автоматически, таким образом, 
делают государство субъектом МП. Для этого нет нужды в каком-либо признании. Признание или непризнание со стороны других государств не содержат в этом смысле каких-либо юридических последствий. Признание или непризнание - это сфера политики.

Есть такая тенденция: государства фактом признания/непризнания все-таки стремятся проявить свою волю, чтобы допустить или не допустить новое государство в круг международного сообщества.

Когда-то признавали только христианские или только монархические государства. Сегодня критерием служат другие политические и идеологические ценности: не признаются государства «недемократические»; государства, нарушающие права человека; государства, утвердившиеся силой; государства, не приверженные миру. Однако все эти политические и идеологические установки не реализованы в нормах МП, хотя и имеются попытки со стороны отдельных государств бюрократизировать процедуру признания (Брюссельские Заявления министров иностранных дел стран ЕЭС от 16.12. 1991 г. по поводу признания «новых государств Восточной Европы и в Советском Союзе»).

Индивиды в МП. Некоторые научные международно-правовые доктрины исходят из того, что субъектами современного МП являются индивиды. По крайней мере, признается их ограниченная правосубъектность. В связи с обязанностью государства обеспечить права человека индивид, например, получает соответствующие права, может прибегнуть для защиты своих прав к международным институтам. Права и обязанность индивидов в широком спектре вытекают также из договоров в рамках ЕC.

Однако можно возразить: все эти права и обязанности индивидов не являются собственно международными. Соответствующие международные договоры лишь вводят во внутренние правопорядки государств-участников новые правовые режимы. В их рамках и реализуются права и обязанности индивидов.

Адресатами международно-правовых норм (обычных или договорных), касающихся прав и обязанностей индивидов, в любом случае остаются только государства.

Право международного сообщества по-прежнему остается «правом управляющих», а не «правом управляемых».

Равным образом не являются субъектами МП группы индивидов, например национальные меньшинства. 
Часто говорят о международной правосубъектности народов («право народов на самоопределение», «право народов на собственные природные ресурсы» и др.), однако термин (народ» в большинстве этих случаев используется в переносном смысле (in modo enfatico), и его свободно можно заменить на термин «государство», если под «государством» понимать «государство - сообщество» (а не «государство аппарат/организацию»).

По-другому дело обстоит только в случае самоопределения, когда «народ» противостоит «государству» и речь идет об «управляемых», а не об «управляющих».

Право на самоопределение. Право народа на самоопределение - это международно-правовой принцип обычно-договорного характера. Однако нелегко вычленить юридическое содержание данного принципа. Практика его применения даже сегодня представляется ограниченной.

Прежде всего он нацелен на самоопределение народов, находящихся под иностранным управлением («внешнее самоопределение» autodeterminazione esterna), под колониальным господством, а также на территориях, захваченных и удерживаемых силой (арабские территорйи, захваченные Израилем после 1967 г.).

Право на самоопределение - это право народа, находящегося под иностранным правлением, на независимость, на присоединение или интеграцию с другим независимым государством, на формирование собственного государства.

Вместе с тем МП требует, чтобы государства пользовались поддержкой большинства народа на основе свободных выборов («внутреннее самоопределение» - autodeterminazione interna) и обязывает государства защищать - при необходимости даже силой - результаты свободного волеизъявления народа.

Международные организации. Наряду с государствами субъектами МП являются международные организации, обладающие собственной самостоятельной правосубъектностью, отличной от правосубъектности государств.

Правосубъектность международных организаций была подтверждена заключением (parere) Международного суда ООН от 20 декабря 1980 г., касавшимся толкования Договора между ВОЗ и Египтом от 25 марта 1951 г. В заключении говорилось: «Международная организация - субъект международного права, связанный как таковой 
всеми обязанностями, вытекающими для него из общих норм международного права, а также из учредительного акта и из договоров, в которых эта организация участвует».

Необходимо различать:

а) международную правосубъектность международной организации;

б) правосубъектность международной организации по внутреннему праву.

Помимо государств и международных организаций в перечень субъектов МП входит католическая церковь. Ее правосубъектность сложилась исторически, подтверждена договорами и существованием Государства Ватикан (Stato della Citta del Vaticano).

Общее МП и международно-правовой обычай. Нормы общего МП носят обычно-правовой характер. Понятие «обычай» мало чем отличается в МП и во внутригосударственном праве. Международный обычай появляется от постоянно повторяющегося и одинакового поведения государств при убеждении, что такое поведение является обязательным, социально необходимым.

Отсюда следует, что для обычая необходимы два элемента:

a) повторяющееся поведение или практика (diuturnitas);

б) юридически обоснованное убеждение в обязательности такого поведения (opinio juris sive necessitatis).

Многие ученые считают, что достаточно и одного - первого - элемента. Однако государства постоянно высказываются в том смысле, что для существования обычая необходим и второй элемент.

Международный суд ООН в своих решениях (sentenze) также многократно опирался на оба элемента обычая (решение от 20 февраля 1969 г. о разграничении континентального шельфа в Северном море; решение от 3 июня 1985 г. о разграничении континентального шельфа между Ливией и Мальтой; решение от 27 июня 1986 г. о военных действиях против Никарагуа).

В качестве подтверждения наличия обычно-правовых норм чаще всего используются международные договоры. Договоры также помогают становлению новых обычно-правовых норм в отношениях между государствами-участниками. Не может считаться обычаем поведение, которое является результатом не практики, а взаимных уступок. Так, по Алжирским соглашениям от 19 января 1981 г. был создан американо-иранский суд (Iran - US Claims Tribunal), для того чтобы рассматривать иски граждан соответствующей страны, если в другой 
стране их имуществу нанесен ущерб. Суд отказался от практики «частичного возмещения» ущерба, которая осуществлялась ранее по так называемым lump - sum agreements. По таким соглашениям государство, которое национализировало/экспроприировало иностранную собственность, выплачивало государству, чьи граждане пострадали в результате национализации/экспроприации, в качестве возмещения некую итоговую сумму, как правило, меньшую, чем действительная стоимость имущества. Американо-иранский суд посчитал, что lump sum agreements - это продукт сделки, взаимных уступок, а не международного обычая.

Поведение, идущее вразрез со сложившейся обычно-правовой нормой, может означать:

a) отрицание сложившейся ранее нормы (desuetidine), создание прецедента в целях образования новой нормы;

б) нарушение МП (а, как известно, нарушения права не создают норм; из противоправных действий не может сложиться международно-правовой обычай). В этом случае государства так или иначе реагируют на нарушение.

Интересно, что в конце 80-x - начале 90-х гг. XX века в научной правовой литературе США развернулся спор о том, могут ли американские суды рассматривать дела о возможных нарушениях со стороны Президента и исполнительной власти норм международных обычаев. В частности, указывалось, что лишить исполнительную власть свободы нарушать обычное право еще не означает исключить ее из процесса замены одних обычно-правовых норм другими, тем более что этот процесс должен осушествляться в соответствии с действующим правом.

Формирование международно-правовых обычаев происходит под воздействием:

а) «внешних» актов государств (договоры, дипломатические ноты, действия в международных органах);

б) «внутренних» актов (законы, судебные решения, подзаконные акты).

Для существования международно-правового обычая нет нужды, чтобы каждое отдельное государство подтверждало его или выражало согласие на применение обычая в отношении себя.

Общее обычное МП обязательно для всех государств, независимо от того, участвовали или не участвовали государства в создании обыч- 
но-правовых норм. Этот принцип, впрочем, оспаривается государствами, появившимися в процессе деколонизации. Многие «новые» государства полагают, что вправе свободно принять лишь те общие обычно-правовые нормы, которые отвечают их интересам и требованиям (например, принцип территориального суверенитета); все остальные нормы «колониального периода» подлежат совместному пересмотру - например, некоторые нормы международного экономического права и международного морского права, касающиеся экономических интересов иностранцев или режима морских ресурсов.

Если общий международно-правовой обычай оспаривается одним государством («постоянным оппонентом» - persistent objector), то это можно игнорировать; если группой государств - то может быть поставлено под сомнение само существование общей обычноправовой нормы.

Для того чтобы модифицировать общее МП, группа развивающихся стран использует, в частности, Генеральную Ассамблею $\mathrm{OOH}$, в которой они обладают численным преимуществом. Некоторые юристы из развивающихся стран (Аби-Сааб) даже заявили, что классический процесс образования норм отныне заменен «квазизаконодательным» процессом в рамках $\mathrm{OOH}$.

С таким подходом нельзя согласиться. Формально резолюции ГА ООН не носят обязываюшего характера, и содержашиеся в них нормы могут стать обязательными только если трансформируются в международные обычаи или договоры. Впрочем, нормы резолюций - часть «мягкого права», и в этом качестве они дают определенный правовой эффект.

Помимо обших международно-правовых обычаев, существуют и партикулярные обычно-правовые нормы регионального или локального характера (например, нормы, действующие между латиноамериканскими странами).

И еще один аспект: общие обычные международно-правовые нормы широко применяются по аналогии в тех сферах, в которых недостаточно правового регулирования. В частности, нормы, касающиеся международного воздушного права, применяются в международном космическом праве.

Общие принципы права в МП. Устав Международного суда ООН (ст. 38) в ряду источников, используемых для разрешения споров между государствами, на третьем месте, после договоров и обычаев, указывает «общие принципы права, признанные цивилизованными госу- 
дарствами». Имеется в виду, что «общие принципы права» играют роль «аналогии права» (analogia juris), когда необходимо восполнить пробел в договорном или обычно-правовом регулировании применительно к конкретному случаю.

Речь идет о более или менее известных принципах правосудия или юридической логики, применяемых в международных отношениях и особенно в рамках международных судов, арбитражей: «последующая норма отменяет предыдущую»; «специальная норма имеет приоритет над общей нормой»; nemo judex in re sua; in claris non fit interpretation; ne bis in idem, - и т.п.

«Общие принципы права» в международной сфере представляют собой группу норм международных обычаев sui generic и постепенно встают в один ряд с международно-правовыми нормами.

Если международное обычное право запрещает только грубые правонарушения, например в сфере прав человека - геноцид, апартеид, пытки, то посредством «общих принципов права» сфера регулируемых международным обычным правом отношений по поводу защиты прав человека расширяется.

Итальянские суды время от времени сталкиваются с казусами, выходящими на проблематику «общих принципов права». Например, в 1967 г. Конституционный суд Италии принял решение по делу о несоответствии Конституции страны статей Уголовного кодекса, позволяющих осудить в Италии человека, уже осужденного в другой стране за преступления, совершенные в Италии. Утверждалось, что подобное положение противоречит «общему принципу права» ne bis in idem.

Другие неписаные общие нормы. Некоторые представители международно-правовой науки (Quadri) считают, что над общими нормами международных обычаев имеется еще одна категория общих неписаных норм - своего рода основополагающие принципы организации международного сообщества. Эти принципы по замыслу представляют собой первичные нормы МП. Среди них есть принципы формальные и материальные.

К формальнымм относятся главным образом два принципа:

1) consuetude est servanda - обычай должен соблюдаться;

2) pacta sunt servanda - договоры должны соблюдаться.

Maтериальные принципы могут быть самыми разными, лишь бы они предопределяли порядок в какой-то материальной сфере отношений (например, «свободы моря»). 
При зрелом размышлении следует признать, что данная концепция принципов неприемлема, поскольку закрепляет положение, при котором группа государств и даже одно только государство, располагающее необходимой силой и влиянием (например, США, гегемонистские устремления которых становятся в последние годы все заметнее), могут навязать свою волю остальным членам международного сообщества. Более сильные и влиятельные силы в конечном итоге, меняя правила, сформируют другие общие нормы в своих интересах, в том числе через правонарушения и злоупотребление правом.

Конечно, и без того в основе многих неписаных норм лежит «навязывание» со стороны (те же «свободы моря» когда-то формировались под воздействием Голландии, затем - Великобритании), но такие нормы становятся общими, если трансформируются в свободное поведение государств, убежденных в социальной необходимости данного поведения. Другими словами, «навязывание» может привести к становлению принципа, только если несет в себе стабильность и устойчивость.

Под влиянием британского права в качестве неписаного источника всех норм МП иногда называют «справедливость» (equita), общее представление о том, что справедливо, а что несправедливо.

Однако международная практика не восприняла эту британскую конструкцию. Да и в случае с пробелами в МП «норма справедливости» не поможет сформулировать право или обязанность государств. В то же время понятие справедливости часто лежит в основе решений международных судов, в частности Международного суда $\mathrm{OOH}$.

О писаных общих нормах МП. Итак, общее международное право состоит из неписаных норм. Существует ли общее писаное МП?

Международное обычное право подвергается кодификации начиная с Гаагских конвенций 1899 и 1907 гг, посвященных правилам войны.

Попытки кодификации предпринимались во времена Лиги Наций, хотя и без особых результатов. И только в рамках ООН кодификационная работа стала постоянной и системной, выразившись в серии многосторонних договоров.

При отсутствии в международном сообществе единого органа с правообразовательными функциями договор является единственным средством перевода неписаного права в писаное.

Договоры, выработанные в процессе кодифицированной работы, в частности в рамках $\mathrm{OOH},-$ это международные договоры, обязывающие только участвующие в них государства. 
Можно предположить: поскольку договоры являются кодификацией международного обычного права, нормы этих договоров в качестве обычных норм должны применяться и к не участвующим в договорах государствам. Однако ясно, что в ходе кодификационной работы общие обычные нормы подвергались своеобразному реконструированию, но выработанные на их основе договорные нормы могут стать общими, только если они соответствуют общей практике. Этот подход проявился в действиях отдельньх государств (решение итальянского суда г. Неаполя от 7 февраля 1974 г. в связи с режимом территориального моря).

В таком ключе высказывался и Международный суд ООН (в решении от 20 февраля 1969 г. по делу о разграничении континентального шельфа в Северном море между ФРГ и прибрежными государствами). Суд, в частности, не признал в качестве общей международно-правовой нормы статью 6 Женевской конвенции 1958 г. о континентальном шельфе, в которой устанавливался критерий для разграничения морского дна между прибрежными государствами.

По мнению суда, данный критерий не подтверждался достаточной и общей практикой государств.

Декларации ГА ООН. С темой общего международного права связан вопрос о Декларациях ГА ООН, содержащих принципы и нормы, касающиеся отношений между государствами, а также внутригосударственных отношений между государством и частными лицами (либо иностранцами).

Декларации не носят обязывающего характера и не являются самостоятельным источником обшего МП. Вместе с тем, с точки зрения прогрессивного развития МП, они играют столь же важную роль, что и многосторонние договоры, выработанные в результате кодификационной работы в рамках $\mathrm{OOH}$.

Декларации являют собой инструмент образования новых международных обычаев, особенно если принимаются единодушно, консенсусом или даже только преобладающим большинством голосов.

Некоторые Декларации или их части сопоставимы с собственно договорами: в них, как правило, фиксируются те или иные международно-правовые принципы, нарушение которых приравнивается к нарушению Устава ООН. Соответственно данные принципы как бы признаются обязательными. В этом смысле Декларации (или их части) можно приравнять к договорам в простой форме и считать их обязательными для государств, которые голосовали за Декларации. 
Договоры в международном партикулярнои праве. Договоры являются важным источником партикулярных норм. Для обозначения данного источника используются, помимо слова «договор», различные термины: трактат, конвенция, пакт, устав, статут, обмен нотами.

Многие авторы, особенно в немецкой международно-правовой доктрине (Triepel), делят договоры на «нормативные договоры» (или «договоры-законы») и «договоры-контракты» («договоры-сделки»). Считается, что только первые из них содержат в полном смысле юридические нормы, направлены на регулирование межгосударственных отношений и на объединение сторон. К таковым, в частности, относятся: кодифицированные договоры; договоры, учреждающие международные организации; конвенции о правах человека и т.п. Вторые же - «договоры-контракты»/»договоры-сделки»-регулируют конкретные правоотношения, являются источниками прав и обязанностей, но не источниками юридических норм, направлены на противопоставление сторон. В таких договорах стороны предоставляют друг другу взаимные возмешения, более или менее сбалансированные, например тот или иной правовой режим для граждан одной страны на территории другой страны. К таким договорам относят, в частности: торговые договоры, союзнические договоры, договоры о территориальных уступках и т.п.

Как представляется, нет смысла в подобном разделении договоров, в противопоставлении норм и правоотношений. В каждом договоре есть элементы как объединения, так и противопоставления сторон. Все договоры содержат правила поведения и обязательны для сторон. В Венской конвенции 1969 г. о праве международных договоров нет и упоминания о подобной классификации договоров, которую можно считать анахронизмом.

Существует еще одна классификация договорных норм, лишенная практического значения. В соответствии с ней выделяют нормы:

a) абстрактные, т.е. направленные на регулирование типовых отношений;

б) конкретные, т.е. предназначенные для разрешения единственной и определенной ситуации.

И, наконец, договоры могут содержать как нормы материальные, так и нормы (итальянский автор нспользует термины formali, strumentali) «формальные», «вспомогательные», «рамочные», «учредительные». 
Под материальными понимаются нормы, которые непосредственно регулируют отношения между сторонами. Под формальными (вспомогательны.ии, рамочными) понимаются нормы, которые являются источниками других норм, например нормы договоров, учреждающих международные организации; нормы, касающиеся образования, изменения международного права, исключений из него; нормы о разрешении споров.

Венская конвенция 1969 г. о праве международных договоров. Подобно тому, как контракты во внутригосударственном праве подчиняются законам, так и международные договоры в МП подчиняются ряду обычно-правовых норм, определяющих процесс образования договорных норм, условия их действия и действительности.

Комплекс такого рода обычно-правовых норм составляет «право международных договоров», кодифицированное в Венской конвенции 1969 г. (ратифицирована Италией в феврале 1974 г.; вступила в силу в январе 1980 г.).

Кроме фундаментальной Конвенции 1969 г. о праве международных договоров, следует упомянуть также Венскую конвенцию 1978 г. о правопреемстве государств в отношении международных договоров (вступила в силу в 1996 г.) и Венскую конвенцию 1986 г. о международных договорах государств с международными организациями или между международными организациями (пока не вступила в силу).

В статье 4 Венской конвенции 1969 г. установлено: «Без ущерба для применения любых норм, изложенных в настоящей Конвенции, под действие которых подпадали бы договоры в силу международного права, независимо от Конвенции, она применяется только к договорам, заключенным государствами после ее вступления в силу в отношении этих государств. Видно, что в первой половине этой статьи речь идет о нормах общего обычного права и, по сути, определяется очевидный принцип: нормы Конвенции, будучи нормами общего международного права, распространяются на все государства и все договоры.

Следует отметить, однако, что в Конвенцни одновременно присутствует много оригинальных - новых - процессуальных норм (например, о сроках по возражениям в отношении оговорок, об условиях недействительности или прекращения договоров и др.).

В связи с этим обратим внимание на вторую половину статьи 4 Венской конвенции 1969 г. - о применении Конвенции к договорам, заключенным после ее вступления в силу в отношении соответствующе- 
го государства. Из нее следует, что:

а) «новые» нормы не обладают ретроактивным характером;

б) «новые» нормы действуют только в отношениях между государствами, применительно к которым Конвенция вступила в силу (т.е. которые ратифицировали Конвенцию).

Международные договоры во избежание «тайной дипломатии» подлежат регистрации в Секретариате ООН (ст. 102 Устава ООН; ст. 80 Венской конвенции 1969 г.). В противном случае государство не может оперировать таким договором в органах $\mathrm{OOH}$.

Договоры в простой форме, заключенные с нарушением внутригосударственной компетенции по заключению международных договоров. Каковы юридические последствия в случае заключения договора с нарушением подписавшей стороной соответствуюшей внутригосударственной компетенции? Очевидно, что проблема касается главным образом договоров, заключаемых в простой письменной форме. И она злободневна для Италии, где нередки случаи, когда исполнительная власть самостоятельно заключает международные договоры (без последующей ратификации) по вопросам, которые по Конституции (ст. 80) требуют участия парламента и президента.

Среди примеров нарушения внутренней компетенции в Италии можно упомянуть следующие: присоединение Италии к Уставу ООН (письмо Министра иностранных дел Италии от 7 мая 1947 г. и решение ГА ООН 1955 г.); Меморандум о взаимопонимании по Триесту от 5 октября 1954 г. заключенный представителями правительств США, Великобритании, Югославии и Италии (от Италии - послом в Великобритании); франко-итальянский обмен нотами от 28 апреля 1964 г. об определении границы в районе Монченизио; целая серия соглашений с США о военном сотрудничестве и взаимопомощи, предоставлении военных баз, размещении ракет и др.).

Каков должен быть подход к таким договорам, заключенным с нарушением внутригосударственной компетенции, определено в статье 46 Венской конвенции 1969 г.: «1. Государство не вправе ссылаться на то обстоятельство, что его согласие на обязательность для него договора было выражено в нарушение того или иного положения его внутреннего права, касающегося компетенции заключать договоры, как на основание недействительности его согласия, если только данное нарушение не было явным и не касалось нормы его внутреннего права особо важного значения. 2. Нарушение является явным, если оно будет 
объективно очевидным для любого государства, действующего в этом вопросе добросовестно и в соответствии с обычной практикой».

Международная практика в этом вопросе неопределенна и противоречива, как и научная доктрина, имеющая представителей разных точек зрения.

Однако, как представляется, ст. 46 Венской конвенции в таких случаях не годится. Договор, заключенный исполнительной властью с нарушением конституционной компетенции, остается актом, лишенным юридического характера и «действует, пока действует». Такой акт становится договором, только если соответствующий орган проявит свою волю и выразит ее в конституционном порядке.

Именно так и произошло в большинстве указанных выше случаев из итальянской практики.

Договоры регионов. Многие административно-территориальные подразделения государств осуществляют международные отношения, заключают договоры и с регионами других стран и даже с государствами по вопросам туризма, организации ярмарок и выставок, по сельскохозяйственной проблематике.

Итальянские области, например, заключили целый ряд таких соглашений:

- в 1973 г. Умбрия с землей (region) Потсдам;

- в 1976 г. Ломбардия с сомалийской областью Бенадир (Benadir), а Валь-д-Аоста - с областью Бассо Шебели (Basso Scebeli);

- в 1984 г. Лацио с мексиканским штатом Сонора (Sonora);

- в 1986 г. Марке (Marche) - с китайской провинцией Шандун (Shandong);

- в 1993 г. Сардиния - с Чехией - и др.

Конституционный суд Италии в 1975 г. вынес «антирегионалистское» решение, указав на отсутствие у итальянских областей компетенции заключать подобные соглашения.

В 1977 г. положение было подкорректировано Декретом Президента № 616: регионам запрешалась деятельность за рубежом без предварительного разрешения правительства.

В решениях по делам 1987-1996 гг. Конституционный суд занял позицию, что регионы, получившие предварительное разрешение правительства, могут заключать в целях развития международного сотрудничества «договоры в полном смысле слова» (т.е. договоры, которые влекут ответственность государства, но лишь в определенной сфере и 
в определенном объеме региональной компетенции, в частности в локальных вопросах экономического, социального и культурного развития). При этом Конституционный суд провел различие между «деятельностью, направленной на международное сотрудничество», и «деятельностью международного характера». В первом случае для заключения договора требуется разрешение правительства; во втором случае международная деятельность регионов ограничивается лишь обменом информацией, таюже требует разрешения правительства, но здесь нет места «договорам, влекущим ответственность государства».

Данная позиция Конституционного суда была воспринята в Декрете Президента Италии № 167 от 31 марта 1994 г.

Зачастую административно-территориальные единицы разных государств заключают между собой договоры в исполнение межгосударственных договоров, например о приграничном сотрудничестве. Соответственно юридическая сила таких межрегиональных договоров проистекает из межгосударственного договора, а сами межрегиональные договоры в классификации источников МП занимают в данном случае место источников «третьего уровня».

Правопреемство государств в отношении договоров. При замене суверенитетов, в случае правопреемства международные права и обязанности государства-предшественника переходят на государство-правопреемника. При этом речь идет о переходе прав и обязанностей, вытекающих только из договоров, потому что нормы межсународного обычая так или иначе одинаково распространяются на все государства, а значит, как на государство-предшественника, так и на государствоправопреемника.

С точки зрения правопреемства договоры можно подразделить на:

1) привязанные к территории (localizzabili), например договоры, устанавливающие активные или пассивные сервитуты; договоры об аренде части территории; договоры, предусматривающие свободу прохождения судов через проливы, каналы и т.п.;

2) не привязанные к территории (non localizzabili), т.e. все остальные договоры, к которым относится основная масса договоров.

В 1996 г. (после ратификации 15-м гасударством) вступила в силу Венская конвенция 1978 г. о правопреемстве государств в отношении договоров.

Между тем практика в сфере правопреемства остается путаной. Применительно к договорам, «привязанным к территории», действует 
общий принцип (закрепленный, среди прочего, и в Венской конвенции 1978 г.): государство-правопреемник связано договорами, заключенными государством-предшественником.

Что касается договоров, «не привязанных к территории», то общим принципом, регулирующим вопросы смены суверенитета применительно к таким договорам, является так называемое «правило tabula rasa»: государство-преемник, за определенными исключениями, не связано договорами государства-предшественника. И именно в этом вопросе многие нормы Венской конвенции 1978 г. не соответствуют действующему обычному праву (например, потому что Конвенция предусматривает применение принципа tabula rasa только в случае появления государств в процессе деколонизации).

(Продолжение следует) 